\title{
Mammary tumor induction in ACI rats exposed to low levels of 17ß-estradiol
}

\author{
SRIVANI RAVOORI ${ }^{1 *}$, MANICKA V. VADHANAM ${ }^{1 *}$, SUNATI SAHOO ${ }^{3}$, \\ CIDAMBI SRINIVASAN $^{4}$ and RAMESH C. GUPTA ${ }^{1,2}$ \\ ${ }^{1}$ James Graham Brown Cancer Center, Departments of ${ }^{2}$ Pharmacology and Toxicology, and ${ }^{3}$ Pathology, University \\ of Louisville, Louisville, KY 40202; ${ }^{4}$ Department of Statistics, University of Kentucky, Lexington, KY 40506, USA
}

Received November 6, 2006; Accepted January 2, 2007

\begin{abstract}
Animal models play a major role in understanding the etiology, molecular mechanisms, strategizing intervention and treatment of human diseases. ACI, an inbred line derived from August and Copenhagen strains, is unique for its susceptibility to estrogen-induced mammary tumors. Histologically and in many molecular aspects, the tumors formed in these rats are similar to human breast cancers. Previous studies have shown high mortality and significant weight loss in this model associated with pituitary gland abnormality. We hypothesized that this could be due to overwhelming the biological system with estrogen. Three groups of female ACI rats (7-8 weeks) received either $3-\mathrm{cm}$ sham silastic implants, or the conventional $3-\mathrm{cm}$ silastic implants containing $27 \mathrm{mg}$ of 17ß-estradiol, or 1.2-cm silastic implants containing $9 \mathrm{mg}$ 173-estradiol. The sham and 3 -cm implant rats were euthanized at 180 days while the $1.2-\mathrm{cm}$ implant rats were euthanized at 240 days. The $1.2-\mathrm{cm}$ implants resulted in significantly reduced serum estrogen levels and pituitary gland size. Animals with 1.2-cm implants had $100 \%$ tumor incidence, while not all rats developed tumors with $3-\mathrm{cm}$ implants. Both the tumor burden (from $1,011 \pm 402$ to $2,324 \pm 454 \mathrm{~mm}^{3}$; $\mathrm{p}=0.01$ ) and tumor multiplicity (from $5.78 \pm 1.4$ to $7.6 \pm 1.04$ ) increased by lowering the estrogen dose, and the inter-animal variability in the tumor indices decreased. Finally, the weight of the pituitary gland was also significantly $(\mathrm{p}=0.0004)$ reduced (from $178 \pm 23.5 \mathrm{mg}$ to $80 \pm 8.9 \mathrm{mg}$ ) and the mortality rate decreased
\end{abstract}

Correspondence to: Dr Manicka V. Vadhanam, Brown Cancer Center, 304B Delia Baxter Research Building, 580 South Preston Street, Louisville, KY 40202, USA

E-mail: mvvadh01@louisville.edu

${ }^{*}$ Contributed equally

Abbreviations: ACI, August Copenhagen Irish; $\mathrm{E}_{2}$, 17ß-estradiol; $\mathrm{H}_{2} \mathrm{O}_{2}$, hydrogen peroxide; PCNA, proliferating cell nuclear antigen; $\mathrm{DAB}$, diaminobenzidine tetrahydrochloride; DCIS, ductal carcinoma in situ

Key words: ACI rats, mammary tumor, 17ß-estradiol from $42 \%$ to $0 \%(\mathrm{p}=0.01)$. Our data indicate that the improvised model will provide valuable insights into the molecular alterations in the estrogen-induced mammary tumorigenesis and will be ideal for inhibition studies.

\section{Introduction}

Estrogens are beneficial for normal growth and development of mammary glands and uterus. However, epidemiological studies in the past few decades have shown increased risk of breast and uterine cancer associated with estrogen exposure $(1,2)$. The role of estrogens in regulation of cell proliferation and breast carcinogenesis has been well documented $(1,3,4)$. Prolonged exposure to high estrogen levels in women has been associated with increased incidence of breast cancer $(2,5,6)$. Estrogen appears to play a dual role in breast cancer progression; as a pro-carcinogen in inducing genetic damage $(7,8)$ and in hormone-stimulated cell proliferation $(9,10)$. However, the exact mechanisms of tumor induction by estrogen remain to be elucidated.

Animal models play a major role in understanding the etiology and molecular mechanisms of human diseases. They help in successful development of intervention and treatment strategies. It is imperative that the model used has similarities in the way the disease is acquired or manifests in humans to better understand the mechanisms involved. ACI rats, a cross between August and Copenhagen rats, have been shown to develop mammary tumors when exposed to several estrogenic compounds and 173 -estradiol $\left(\mathrm{E}_{2}\right)(11,12)$. This model is suitable to study mammary tumorigenesis since $\mathrm{E}_{2}$-mediated tumor induction is more translatable to the human scenario than animal models that develop tumors with exposure to chemical carcinogens and physical carcinogens, due to mechanistic differences (13). Furthermore, the histological and molecular aspects of ACI rat mammary tumors are comparable to human breast cancers. ACI rats have been used to study the mechanism of estrogenic substances in tumor formation in mammary tissues. Several investigators have implanted these rats with cholesterol pellets containing diethylstilbestrol to study tumorigenesis $(14,15) . \mathrm{E}_{2}$ was administered by silastic implants to induce tumors by Shull et al (13) and later, Li et al (16) demonstrated similar findings using $\mathrm{E}_{2}$ encapsulated in cholesterol pellets. However, morbidity and mortality 
associated with pituitary tumors has remained a major concern. While most of the rats develop severe sickness symptoms, some of the rats die from pituitary tumors, even before the development of mammary tumors. The associated morbidity might be a concern in the interpretation of the mechanism of estrogen-induced carcinogenesis in mammary tissue.

In the present study, we dramatically reduced pituitary tumor-associated morbidity and mortality in this model, which was a major setback, limiting its applications. Thus, this improvised model may be best suited for chemoprevention studies and testing therapeutic agents targeting estrogenmediated mammary cancer development.

\section{Materials and methods}

Chemicals. 17ß-estradiol was purchased from Steraloids, Inc. (Newport, RI). All other chemicals were analytical grade unless otherwise specified.

Animals. Six- to 7-week-old female ACI rats were purchased from Harlan Sprague-Dawley, Inc. (Indianapolis, IN). The rats were housed in cages and fed food and water ad libitum and acclimatized for a week. The rats received AIN-93M purified diet (Harlan Teklad, Inc., Madison, WI) for the entire study.

Implants. The silastic tube $(2.0 \times 3.2 \mathrm{~mm}$; i.d. x o.d.) was purchased from Allied Biomedical, Inc. (Ventura, CA) and medical-grade silicone adhesive was purchased from Factor II, Inc. (Lakeside, AZ). Implants were prepared as described by Wiklund et al (17), and followed by Shull et al (13). The implants were $3 \mathrm{~cm}$ and $1.2 \mathrm{~cm}$ in length, containing $27 \mathrm{mg}$ and $9 \mathrm{mg}$ of $\mathrm{E}_{2}$, respectively. The effective length of the tube available for compound delivery was $2.8 \mathrm{~cm}$ and $1.0 \mathrm{~cm}$, respectively.

Treatment. The animals were weighed and anesthetized by isofluorane inhalation and transferred to a warm bed with a nose cone for anesthetizing agent. A small area on the back of the animal was shaved and cleaned with $70 \%$ ethanol. An approximately $1-\mathrm{cm}$ incision was made in the clean shaved area and blunt forceps were used to separate the skin from the underlying subcutaneous tissue to create a cavity. The implant was inserted into the subcutaneous cavity and closed using a sterile 9-mm clip. The animals were immediately transferred to the cage with warm bedding for $1 \mathrm{~h}$ and monitored for any surgery-related injuries, before being transferred to their respective cages. The clip was removed after 2 weeks, when the wound was completely healed. The animals were weighed every 2 weeks. Six rats from each group were sacrificed at the end of 90 days after $E_{2}$ implant to study short-term effects of the estradiol implants. Blood, liver, mammary and pituitary tissues were collected and their weights were recorded. A portion of the tissues were fixed in $10 \%$ buffered formalin and remaining tissues were snap frozen and stored at $-80^{\circ} \mathrm{C}$ for future use. The remaining $3-\mathrm{cm}$ and $1.2-\mathrm{cm}$ implant rats were sacrificed at 180 and 240 days, respectively, after $E_{2}$ implant. If the rats were found morbid or when the largest tumor reached approximately $1.5 \mathrm{~cm}$, they were euthanized pre-term. The findings were recorded and tissues collected and stored appropriately. The location, number and size (measured using vernier calipers) of tumors were recorded. Blood was collected for serum $\mathrm{E}_{2}$ and plasma prolactin analyses, and mammary gland, including tumors, pituitary gland and liver were harvested. A portion of the tissues were fixed in $10 \%$ buffered formalin and processed for histopathological and immunohistochemical analyses.

Serum $E_{2}$. Circulating serum $\mathrm{E}_{2}$ was analyzed from blood samples by electrochemiluminescent detection using the Roche E170 immunoassay analyzer at the University Hospital's Clinical Chemistry facility. The detection range for this method is $5-4300 \mathrm{pg} / \mathrm{ml}$. An estradiol II reagent kit was purchased from Roche Diagnostics, Inc. (Indianapolis, IN) and conditions were followed as per the manufacturer's instructions. The assay was calibrated using the standards provided by the vendor. All samples were assayed in duplicate.

Plasma prolactin. Levels of plasma prolactin, secreted by the pituitary prolactinomas were determined using the Rat Prolactin EIA kit (Alpco Diagnostics, Windham, NH). Limited serum samples were analyzed in parallel to rule out interference from heparin.

Histology and immunohistochemistry. Five-micron sections cut from paraffin blocks of mammary and pituitary tissues were dewaxed and rehydrated through graded ethanol to water for routine $\mathrm{H} \& \mathrm{E}$ staining and immunohistochemistry. Endogenous peroxidase was blocked with $3 \% \mathrm{H}_{2} \mathrm{O}_{2}$ for $10 \mathrm{~min}$. Antigen retrieval was carried out by boiling the sections in a $0.01-\mathrm{M}$ citrate buffer, $\mathrm{pH} 6.0$, for $40 \mathrm{~min}$ in a water bath. Sections were stained for proliferating cell nuclear antigen (PCNA) using a Zymed ready-to-use kit (Invitrogen Co., Carlsbad, CA). For Ki-67 staining, sections were incubated with Ki-67 antibody (clone MIB-5) (Dako, Glostrup, Denmark) at a dilution of 1:50 for $30 \mathrm{~min}$. Secondary antibody treatment and detection was carried out using a Dako LSAB universal detection kit. Sections were washed with 2 changes of phosphate-buffered saline (PBS) for 3 min between steps. The avidin-biotin complex (ABC) method was used according to the manufacturer's instructions for both the antibodies and color was developed with 3,3'-diaminobenzidine tetrahydrochloride (DAB), and counterstained with hematoxylin, dehydrated with a series of ethanol, cleared with xylene and mounted. For negative controls, primary antibody was replaced with PBS. Sections were viewed under a bright-field microscope. Positively-stained cells were scored per 100 cells per field and 10 such fields were scored. Slides were blinded and scored by 3 cytopathologists and average values are presented.

Statistical analyses. Differences between the means of the treatments were calculated for serum $\mathrm{E}_{2}$ levels, liver, mammary and pituitary weights, body weight, tumor multiplicity and tumor volume, at 90 days and 180/240 days after $\mathrm{E}_{2}$ treatment and p-values were determined by Student's t-test. Serum $\mathrm{E}_{2}$ levels, tissue weights and body weights were compared using ANOVA. Tumor multiplicity was analyzed using the Negative-Binomial-regression model with logarithmic link. Tumor volume was compared using the non-parametric van der Waarden test. 


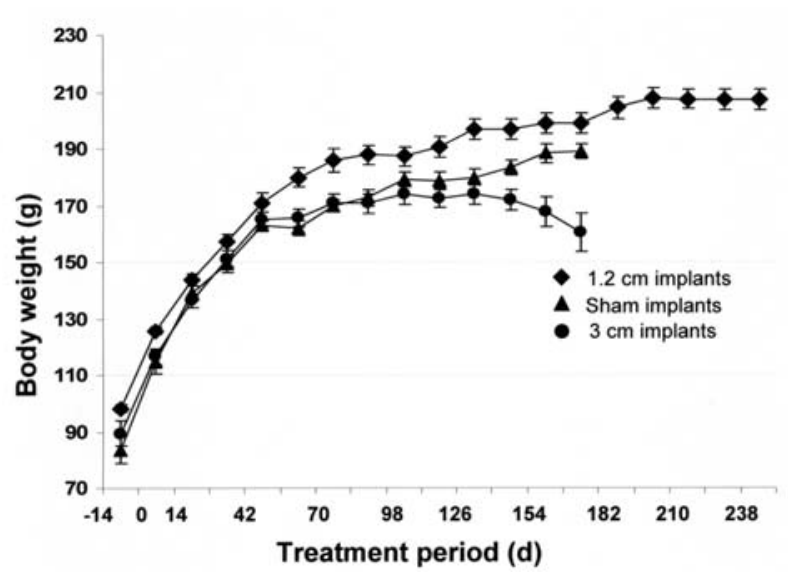

Figure 1. Effect of 3-cm and 1.2-cm 17ß-estradiol implants on body weight.

\section{Results}

General observations. The rats with $3-\mathrm{cm}$ implants showed symptoms of ill health which include rough hair coat, stooped spine, loss of balance and, finally, a $42 \%$ mortality rate. However, the survival rate was $100 \%$ in the $1.2-\mathrm{cm}$ implant group with no or very minimal signs of sickness at termination.

Body weight. There was no difference in the body weight between sham-treated and 3-cm implant rats at 90 days, while it was higher in rats with $1.2-\mathrm{cm}$ implants. The $3-\mathrm{cm}$ implant rats started losing weight from around 133 days after $\mathrm{E}_{2}$ implants until termination (180 days). Of the 12 rats with 3-cm implants, 4 animals were terminated between 131 and 155 days due to morbidity and sickness. The rats with $1.2-\mathrm{cm}$ implants did not show any adverse symptoms until the end of the treatment period (240 days) and had a body weight slightly higher than the control rats (Fig. 1). Significant differences were observed in the body weight between the two $\mathrm{E}_{2}$ treated groups at 90 and 180 days $(\mathrm{p}=0.0081 ; \mathrm{p}<0.0001)$. No significant gain in body weight was observed in the $1.2-\mathrm{cm}$ implant group between 180 days and 240 days $(p=0.146)$ as the growth plateaued around 200 days (Fig. 1).

Circulating $E_{2}$ levels. The serum $\mathrm{E}_{2}$ levels in the $3 \mathrm{~cm}-$ and 1.2-cm implant rats were significantly higher than in the untreated group (Table I). At 90 days, the circulating $\mathrm{E}_{2}$ levels were 3.6-fold higher in the 3-cm implant rats compared to the sham treated, while only a 1.3 -fold increase was observed in the $1.2-\mathrm{cm}$ implant rats. Similarly at 180 days, a 6.8 -fold increase was observed in the 3 -cm implant rats and a 3.8-fold increase was observed at 240 days in the $1.2-\mathrm{cm}$ implant rats.

Plasma prolactin. Plasma prolactin levels increased by 19 and 8 -fold at 90 days in the $3-\mathrm{cm}$ and $1.2-\mathrm{cm}$ implant groups $(\mathrm{p}=0.0013$ and $\mathrm{p}<0.0001)$, respectively, compared with the sham treated (Table I). At termination, prolactin levels increased by 47 - and 27 -fold in the 2 groups $(p<0.0001$ and $\mathrm{p}=0.0003$ ). The differences in prolactin levels between the two implant groups at both 90 days $(\mathrm{p}=0.0208)$ and at termination $(p=0.0037)$ were significant. Corresponding serum samples processed in parallel from 1 rat per group gave comparable results (data not shown) indicating that the commercial serum prolactin kit is also suitable for plasma.

Liver, mammary and pituitary weights. The wet weight of the liver and mammary tissues correlated with the body weight. At 90 days, the liver weight increased by $2 \mathrm{~g}$ in the $3-\mathrm{cm}-$ implant rats and $3 \mathrm{~g}$ in the $1.2-\mathrm{cm}$ implant rats, while mammary tissue weight increased by nearly 2 - and 3 -fold, respectively (Table I). However, at the termination of the experiment, the liver weight declined significantly and a moderate decrease

Table I. Effect of 3-cm and 1.2-cm 17ß-estradiol implants on body weight, organ weight and circulating hormone levels in ACI rats.

\begin{tabular}{|c|c|c|c|c|c|c|c|c|c|}
\hline $\begin{array}{l}\text { Silastic } \\
\text { implant }\end{array}$ & $\begin{array}{l}\text { Amount of } \\
\mathrm{E}_{2}(\mathrm{mg})\end{array}$ & $\begin{array}{c}\text { Treatment } \\
\text { period (days) }\end{array}$ & $\begin{array}{l}\text { No. of rats } \\
\text { per group }\end{array}$ & $\begin{array}{c}\text { Body } \\
\text { weight }(\mathrm{g})\end{array}$ & $\begin{array}{c}\text { Liver } \\
\text { weight }(\mathrm{g})\end{array}$ & $\begin{array}{l}\text { Mammary } \\
\text { weight }(g)\end{array}$ & $\begin{array}{c}\text { Pituitary } \\
\text { weight }(\mathrm{g})\end{array}$ & $\begin{array}{c}\text { Plasma prolactin } \\
(\mathrm{ng} / \mathrm{ml})\end{array}$ & $\begin{array}{c}\text { Serum } E_{2} \\
(\mathrm{pg} / \mathrm{ml})\end{array}$ \\
\hline Sham & - & 90 & 6 & $175.6 \pm 2.6$ & $5.1 \pm 0.1$ & $2.3 \pm 0.1$ & $4.3 \pm 0.6$ & $285 \pm 41$ & $51 \pm 5$ \\
\hline $3 \mathrm{~cm}$ & 27 & 90 & 6 & $174.2 \pm 3.5$ & $6.9 \pm 0.2$ & $4.4 \pm 0.2$ & $62.1 \pm 5.9$ & $5,413 \pm 1,233$ & $186 \pm 9$ \\
\hline \multirow[t]{4}{*}{$1.2 \mathrm{~cm}$} & 9 & 90 & 6 & $196.5 \pm 2.3$ & $7.9 \pm 0.2$ & $6.4 \pm 0.2$ & $7.9 \pm 3.5$ & $2,198 \pm 257$ & $65 \pm 5$ \\
\hline & & & & $0.8656^{\mathrm{a}}$ & $<0.0001^{\mathrm{a}}$ & $0.001^{\mathrm{a}}$ & $<0.0001^{\mathrm{a}}$ & $0.0013^{\mathrm{a}}$ & $0.0166^{\mathrm{a}}$ \\
\hline & & & & $0.0172^{b}$ & $<0.0001^{\mathrm{b}}$ & $<0.0001^{\mathrm{b}}$ & $0.0003^{\mathrm{b}}$ & $<0.0001^{\mathrm{b}}$ & $0.7905^{b}$ \\
\hline & & & & $0.0081^{\mathrm{c}}$ & $0.0166^{c}$ & $0.0014^{\mathrm{c}}$ & $0.002^{\mathrm{c}}$ & $0.0208^{c}$ & $0.0448^{c}$ \\
\hline Sham & - & 180 & 6 & $185 \pm 2$ & $4.6 \pm 0.1$ & $3.2 \pm 0.3$ & $9.6 \pm 0.5$ & $312 \pm 61$ & $53 \pm 5$ \\
\hline $3 \mathrm{~cm}$ & 27 & 180 & 12 & $156.6 \pm 7.3$ & $4.8 \pm 0.2$ & $3.9 \pm 0.4$ & $177.5 \pm 23.5$ & $14,601 \pm 577$ & $358 \pm 46$ \\
\hline \multirow[t]{4}{*}{$1.2 \mathrm{~cm}$} & 9 & 240 & 15 & $198.5 \pm 4$ & $6.6 \pm 0.2$ & $5.5 \pm 0.3$ & $79.9 \pm 8.9$ & $8,476 \pm 1,521$ & $200 \pm 44$ \\
\hline & & & & $0.0004^{\mathrm{a}}$ & $0.6239^{a}$ & $0.1697^{\mathrm{a}}$ & $<0.0001^{\mathrm{a}}$ & $<0.0001^{\mathrm{a}}$ & $<0.0001^{\mathrm{a}}$ \\
\hline & & & & $0.0504^{\mathrm{b}}$ & $<0.0001 \mathrm{~b}$ & $<0.0001^{\mathrm{b}}$ & $<0.0001^{\mathrm{b}}$ & $<0.0003^{\mathrm{b}}$ & $0.0047^{\mathrm{b}}$ \\
\hline & & & & $<0.0001^{\mathrm{c}}$ & $<0.0001^{\mathrm{c}}$ & $0.0006^{\mathrm{c}}$ & $0.0004^{\mathrm{c}}$ & $0.0037^{\mathrm{c}}$ & $0.0008^{c}$ \\
\hline
\end{tabular}

$\mathrm{p}<0.05$ is considered significant. Values presented are mean \pm SEM. p-values compared between: ${ }^{\text {asham }}$ and 3-cm implant groups; ${ }^{\mathrm{b}} \mathrm{Sham}$ and $1.2-\mathrm{cm}$ implant groups; ${ }^{\mathrm{c}} 3$-cm and $1.2-\mathrm{cm}$ implant groups. 
Table II. Effect of 3-cm and 1.2-cm 17ß-estradiol implants on tumor indices in the ACI rat model.

\begin{tabular}{|c|c|c|c|c|c|c|c|c|}
\hline $\begin{array}{l}\text { Silastic } \\
\text { mplant }\end{array}$ & $\begin{array}{l}\text { Amount } \\
\text { of } E_{2}(m g)\end{array}$ & $\begin{array}{l}\text { Treatment } \\
\text { period (days) }\end{array}$ & $\begin{array}{l}\text { No. of rats } \\
\text { per group }\end{array}$ & $\begin{array}{l}\text { No. of rats euthanized } \\
\text { due to sickness }\end{array}$ & $\begin{array}{l}\text { No. of rats } \\
\text { with tumors }\end{array}$ & $\begin{array}{l}\text { Tumor } \\
\text { multiplicity }\end{array}$ & $\begin{array}{l}\text { Tumor volume } \\
\qquad\left(\mathrm{mm}^{3}\right)\end{array}$ & $\begin{array}{l}\text { Volume per } \\
\text { tumor }\left(\mathrm{mm}^{3}\right)\end{array}$ \\
\hline
\end{tabular}

\begin{tabular}{|c|c|c|c|c|c|c|c|c|}
\hline Sham & - & 90 & 6 & 0 & - & - & - & - \\
\hline $3 \mathrm{~cm}$ & 27 & 90 & 6 & 0 & $1 / 6$ & - & - & - \\
\hline $1.2 \mathrm{~cm}$ & 9 & 90 & 6 & 0 & $0 / 6$ & - & - & - \\
\hline Sham & - & 180 & 6 & 0 & - & - & - & - \\
\hline $3 \mathrm{~cm}$ & 27 & 180 & 12 & 4 & $9 / 12$ & $5.8 \pm 4.18$ & $1,011 \pm 402$ & $164 \pm 66$ \\
\hline $1.2 \mathrm{~cm}$ & 9 & 240 & 15 & 0 & $15 / 15$ & $7.6 \pm 4.03$ & $2,324 \pm 454$ & $345 \pm 60$ \\
\hline
\end{tabular}

${ }^{a} \mathrm{p}-$ value, $\mathrm{p}<0.05$ is considered significant. Values presented are mean \pm SEM.
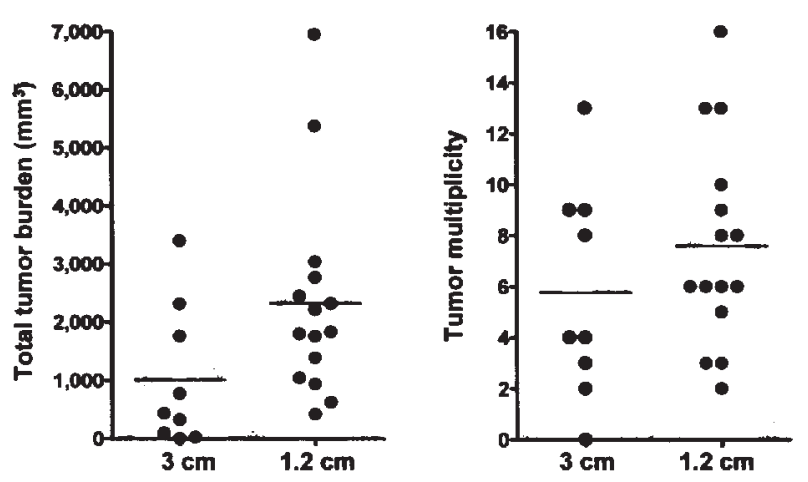

Figure 2. Mammary tumor burden and multiplicity in $\mathrm{E}_{2}$-treated rats. Scatter diagrams reveal the increase in the tumor burden $(\mathrm{p}=0.0125)$ and tumor multiplicity $(\mathrm{p}=0.073)$ in the smaller implant group at termination. Bars represent mean value.

in the mammary tissue weight was observed in the $3-\mathrm{cm}$ implant rats. The decreases in liver and mammary weights with $1.2-\mathrm{cm}$ implants were not statistically significant. The weight of pituitary gland was 2-fold higher in the 3-cm implant group as compared with the smaller implant group both at 90 days and termination (Table I).

Tumor volume and multiplicity. At the termination of the study, a slight but insignificant increase in the tumor multiplicity was observed with 1.2-cm estrogen implants compared with larger implants $(\mathrm{p}=0.073)$; however, the tumor volume increased by nearly 2 -fold $(\mathrm{p}=0.0125)$ (Table II). Noteworthy is the reduction in inter-animal variability in both the tumor volume and multiplicity with shorter implants (Fig. 2). All the rats with $1.2-\mathrm{cm}$ implants developed tumors before termination, which was not the case with the larger implant group. There was also a significant difference in the calculated average volume per tumor between the 2 groups $(\mathrm{p}=0.0154)$, with the volume being nearly 2 -fold greater in the $1.2-\mathrm{cm}$ implant group.

\section{Histopathology}

Mammary glands. The untreated and sham-implanted rats showed normal mammary morphology both at 90 and 180 days. At 90 days, the mammary glands of all the rats with 3-cm and 1.2-cm implants demonstrated a moderate degree of lobular hyperplasia. While some 3-cm implanted rats showed a palpable $(6 \mathrm{~mm})$ large duct papillary in situ carcinoma and a microscopic focus of atypical ductal epithelial hyperplasia $(\mathrm{ADH})$ involving one ductile, none of the rats with a $1.2 \mathrm{-cm}$ implant developed ADH or DCIS (ductal carcinoma in situ) before the 90-day time point (Fig. 3). At termination nine of 12 rats showed either microscopic or macroscopic evidence of in situ ductal carcinomas. All the rats in the 1.2-cm implant group developed tumors and some of the large duct tumors were larger than those detected in the 3-cm implant rats, which was most likely due to continued growth of these tumors for a longer time (Fig. 4).

Pituitary gland. The pituitary gland showed no change with the sham treatment and was small and normal both at 90 and 180 days. At 90 days 3 of 6 rats in the 3-cm implant group showed an indication of microadenoma formation. In contrast, the pituitary in 4 of 6 rats in the 1.2-cm implant group revealed mild enlargement and congestion without microadenoma formation. Both the implant groups had an enlarged pituitary (Fig. 5). At termination, the gland size, which was enlarged nearly 3-4 times in the 3-cm implant rats compared with sham-treated rats, was only twice the size with the smaller implants. The enlargement was mostly due to development of pituitary adenoma with marked congestion and/or hemorrhage (Fig. 6). The pituitary gland in the $3-\mathrm{cm}$ implant rats invariably showed diffuse congestion with fresh hemorrhage within the tumor. Rats with smaller implants showed a lesser degree of congestion and hemorrhage, and the congestion and hemorrhage was seen in fewer animals in this group. Thus, the 1.2-cm implant rats survived longer since the chance of dying from pituitary hemorrhage was markedly delayed.

Cell proliferation markers. PCNA was detected by immunohistochemistry in the nucleus of normal, hyperplastic and carcinomatous mammary tissues (Figs. 3 and 4). No significant difference in the staining was observed for PCNA and Ki-67 in the mammary tissues between the two $\mathrm{E}_{2}$-implanted groups. In contrast, in the pituitary tissues, significantly increased proliferation was observed in the larger implant group 

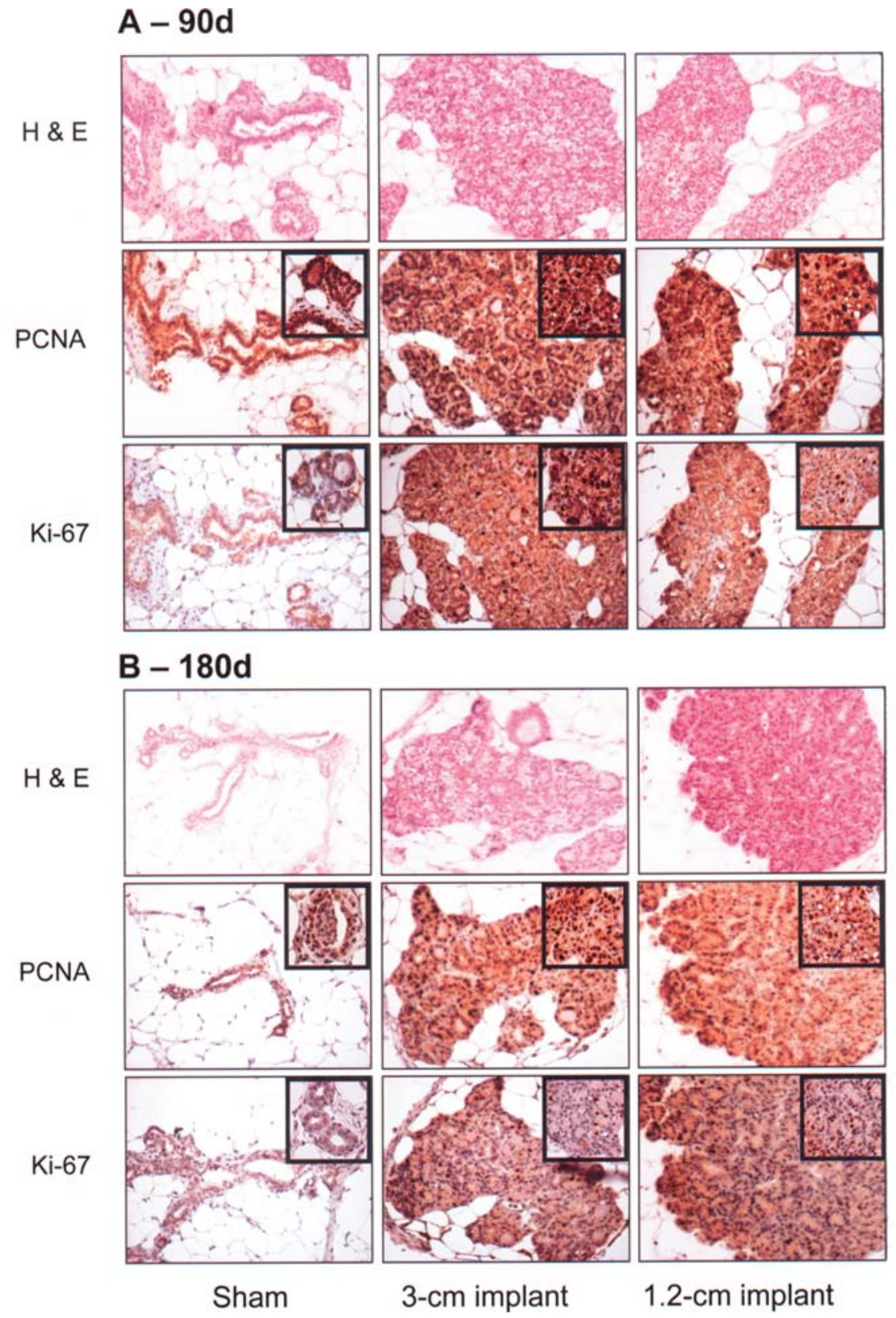

Figure 3. Immunohistochemical evaluation of proliferation markers in mammary tissues. PCNA and Ki-67 were assessed in the ACI rat mammary tissue, 90 days (A) 180 days (3-cm implant) and 240 days (1.2-cm implant) (B) following treatment with $\mathrm{E}_{2}$. Corresponding sections were stained with hematoxylin and eosin. Photomicrographs were taken at x100 and x400 (inset) magnifications.

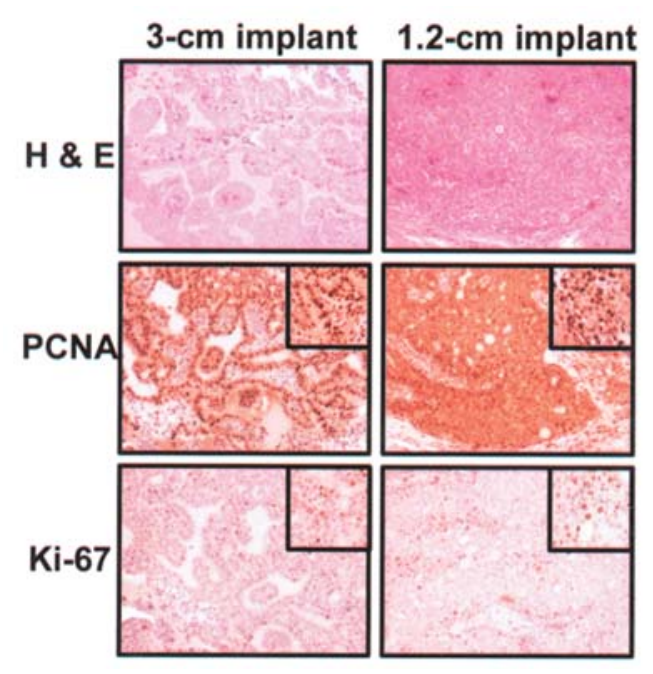

Figure 4. Immunohistochemical evaluation of the proliferation markers in mammary tumors. PCNA and Ki-67 were assessed in the ACI rat mammary tumors at termination after treatment with $\mathrm{E}_{2}$. Corresponding sections were stained with hematoxylin and eosin. Photomicrographs were taken x100 and x400 magnifications.

compared with the 1.2-cm implant group (Fig. 6) at both time points. Percentage positivity of the proliferation markers for both the organs at both time points are tabulated (Table III).

\section{Discussion}

The sensitivity of the ACI rat model to estrogen makes it ideal to study the mechanism of estrogen-induced mammary 
$90 \mathrm{~d}$

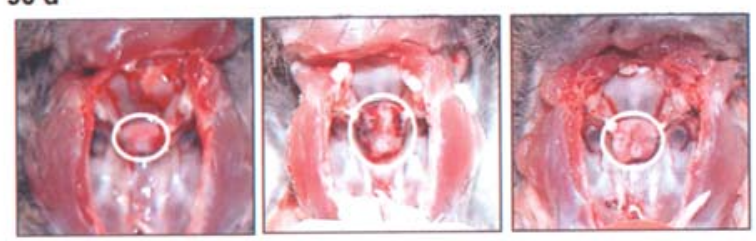

\section{$180 \mathrm{~d} / 240 \mathrm{~d}$}

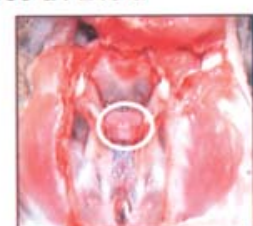

Control

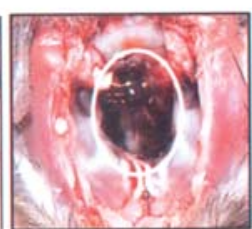

3-cm implant

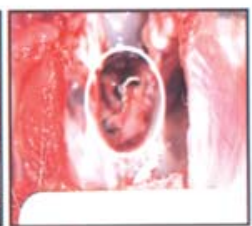

1.2-cm implant
Figure 5. Morphological changes in the pituitary gland of control and $\mathrm{E}_{2}$-treated ACI rats. Rats with $3-\mathrm{cm}$ (90 and 180 days) and 1.2-cm implants (90 and 240 days) had enlarged pituitary glands (white circle) when compared to controls. The pituitary tumors of the larger implant group were almost twice the size of those of the smaller implant group. epithelial transformation. The model exhibits tumor morphology that is similar to human breast carcinomas. Therefore, molecular alterations in the process of tumorigenesis in this model would provide valuable insights into estrogen-induced oncogenesis.

Studies have shown that extended treatment with estrogen results in benign pituitary tumors that produce prolactin in many rat strains $(18,19)$. Estrogen-sensitive rat strains develop mammary tumors with an increase in plasma prolactin levels, and hyperprolactinemia due to pituitary tumors is, in fact, considered as one of the major causative factors for development of estrogen-induced mammary tumors $(20,21)$. While the ACI rat model is ideal to study estrogen-induced mammary tumorigenesis, associated problems arising with pituitary tumors do not provide a sufficient window to utilize this model for several other studies such as intervention. In this study, we have shown that by restricting the amount of estrogen delivered, it is possible to restrict the size of pituitary tumors, and yet induce mammary tumors thereby keeping the pituitary tumor associated morbidity and mortality at bay.
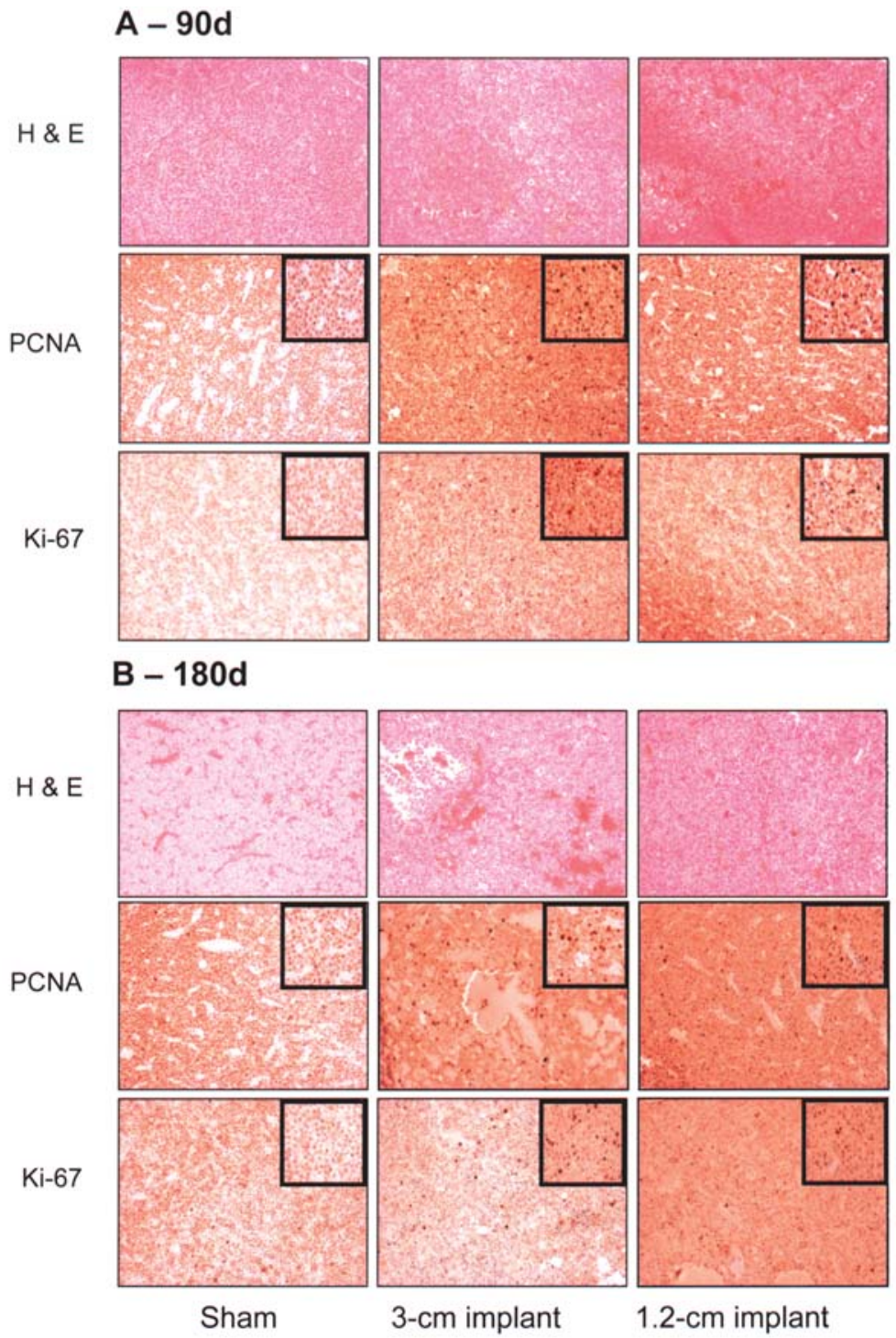

Figure 6. Immunohistochemical evaluation of the proliferation markers in pituitary gland. PCNA and Ki-67 were assessed in the ACI rat pituitary gland, 90 days (A), and 180 days (3-cm implant) and 240 days (1.2-cm implant) (B) after treatment with $\mathrm{E}_{2}$. Corresponding sections were stained with hematoxylin and eosin. Photomicrographs were taken at x100 and x400 (inset) magnifications. 
Table III. Immunohistochemical evaluation of proliferative markers PCNA and Ki-67 in mammary and pituitary tissues.

\begin{tabular}{|c|c|c|c|c|c|c|}
\hline & $\begin{array}{c}\text { Treatment } \\
\text { period (days) }\end{array}$ & Group & $\begin{array}{l}\text { PCNA \% } \\
\text { positivity }\end{array}$ & p-values & $\begin{array}{l}\text { Ki-67\% } \\
\text { positivity }\end{array}$ & p-values \\
\hline \multirow{6}{*}{$\begin{array}{l}\text { Mammary } \\
\text { tissue }\end{array}$} & 90 & Sham & $59.4 \pm 6.7$ & $0.0149^{\mathrm{a}}$ & $3.0 \pm 2.9$ & $0.0633^{\mathrm{a}}$ \\
\hline & 90 & 3-cm implant & $87.1 \pm 4.7$ & $0.0007^{b}$ & $14.1 \pm 3.4$ & $<0.0001^{\mathrm{b}}$ \\
\hline & 90 & 1.2-cm implant & $97.6 \pm 2.4$ & $0.0682^{\mathrm{c}}$ & $14.7 \pm 2.3$ & $0.8755^{\mathrm{c}}$ \\
\hline & 180 & Sham & $5.8 \pm 3.2$ & $0.0004^{\mathrm{a}}$ & $1.2 \pm 0.9$ & $0.0096^{\mathrm{a}}$ \\
\hline & 180 & 3-cm implant & $80.7 \pm 9.7$ & $<0.0001^{\mathrm{b}}$ & $9.8 \pm 2.6$ & $0.0053^{b}$ \\
\hline & 240 & 1.2-cm implant & $80.3 \pm 6.4$ & $0.9715^{\mathrm{c}}$ & $7.2 \pm 1.3$ & $0.3234^{\mathrm{c}}$ \\
\hline \multirow{6}{*}{$\begin{array}{l}\text { Pituitary } \\
\text { tissue }\end{array}$} & 90 & Sham & $2.4 \pm 1.5$ & $<0.0001^{\mathrm{a}}$ & $0.0 \pm 0.0$ & \\
\hline & 90 & 3-cm implant & $77.8 \pm 6.4$ & $<0.0001^{\mathrm{b}}$ & $10.0 \pm 2.1$ & $0.0129^{c}$ \\
\hline & 90 & 1.2-cm implant & $57.5 \pm 4.2$ & $0.037^{\mathrm{c}}$ & $1.8 \pm 1.2$ & \\
\hline & 180 & Sham & $5.8 \pm 1.8$ & $<0.0001^{\mathrm{a}}$ & $0.0 \pm 0.0$ & \\
\hline & 180 & 3-cm implant & $82.2 \pm 2.7$ & $0.0034^{\mathrm{b}}$ & $20.0 \pm 2.6$ & $0.0002^{\mathrm{c}}$ \\
\hline & 240 & 1.2-cm implant & $60.2 \pm 2.3$ & $0.0003^{\mathrm{c}}$ & $4.2 \pm 0.5$ & \\
\hline
\end{tabular}

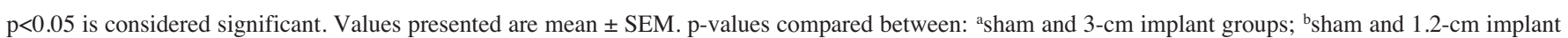
groups; ${ }^{\mathrm{c}} 3 \mathrm{~cm}$ and 1.2-cm implant groups.

Although the rats with 1.2-cm implants developed pituitary tumors, they were smaller and less hemorrhagic than with the 3-cm implants, and therefore the morbidity and mortality associated with pituitary pathology was brought down to virtually nil. The size of the pituitary was reduced to nearly one half with 1.2-cm implants compared with the longer implants, although the adenomas were histologically similar. The weight of the pituitary gland dropped significantly in the shorter implant group, both at 90 days as well as at termination. This data is supported by the plasma prolactin levels that were down by 2.5 - and 1.7 -fold at 90 days and at termination, respectively, in the 1.2-cm implant group.

From the histopathological analysis, it is evident that the development of lobular hyperplasia occurs very early on with estrogen exposure irrespective of the dose. However, the development of early signs of abnormality, i.e. atypical ductal hyperplasia and microscopic areas of DCIS, is dependent upon the amount of estrogen. These changes were detected at 90 days in some of the rats receiving $3-\mathrm{cm}$ implants but not with 1.2-cm implants. By reducing the dosage of estrogen, we have shown that the development of tumor progression is delayed. Nevertheless, all experimental animals developed mammary tumor with less estrogen (1.2-cm implant group) at 240 days.

The lack of significant difference in the proliferative indices (PCNA and Ki-67) between the two groups in mammary tissue suggests that the shorter implant with lesser estrogen was sufficient to elicit a proliferative response and subsequent tumor formation. In contrast, a significant reduction of pituitary proliferation was found, highlighting the negative effect of excessive estrogen on the pituitary gland in the $3-\mathrm{cm}$ implant group. We believe that the high mortality associated with the existing model could be due to overdose of estrogen. The amount of $\mathrm{E}_{2}$ released from the 1.2-cm implants was enough to induce proliferation and transformation of the mammary epithelial cells. The reduction in mortality that we established with the ACI rats is a significant improvement of the model.

Though estrogen has been implicated in mammary carcinogenesis, the exact mechanism of its action has been elusive. This improvised model will be useful in understanding the mechanism by which $\mathrm{E}_{2}$ induces cell proliferation and transformation, and also in chemoprevention studies. By using appropriate methods, the different molecular mechanisms of the transformation process may be better understood. The improvised model would provide valuable insights into the molecular alterations in the estrogen-induced mammary tumorigenesis and be ideally suitable to study known chemopreventive agents as well as therapeutic agents.

\section{Acknowledgements}

This study was supported by the USPHS grant CA-90892 (to R.C.G.) and in part from James Graham Brown Cancer Center and the Agnes Brown Duggan Endowment. Dr Jose Thaiparambil and Mr. Jeyaprakesh Jeyabalan are acknowledged for their assistance in part of the animal procedures, and Dr James Shull for discussion.

\section{References}

1. Sutherland RL, Reddel RR and Green MD: Effects of oestrogens on cell proliferation and cell cycle kinetics. A hypothesis on the cell cycle effects of antioestrogens. Eur J Cancer Clin Oncol 19: 307-318, 1983.

2. Russo IH and Russo J: Role of hormones in mammary cancer initiation and progression. J Mammary Gland Biol Neoplasia 3: 49-61, 1998.

3. Soderqvist G: Effects of sex steroids on proliferation in normal mammary tissue. Ann Med 30: 511-524, 1998. 
4. Anderson E and Clarke RB: Steroid receptors and cell cycle in normal mammary epithelium. J Mammary Gland Biol Neoplasia 9: 3-13, 2004.

5. Lamote I, Meyer E, Massart-Leen AM and Burvenich C: Sex steroids and growth factors in the regulation of mammary gland proliferation, differentiation, and involution. Steroids 69: 145-159, 2004.

6. Anderson E: The role of oestrogen and progesterone receptors in human mammary development and tumorigenesis. Breast Cancer Res 4: 197-201, 2002.

7. Hurh YJ, Chen ZH, Na HK, Han SY and Surh YJ: 2-Hydroxyestradiol induces oxidative DNA damage and apoptosis in human mammary epithelial cells. J Toxicol Environ Health 67: 1939-1953, 2004.

8. Liehr JG: Genotoxicity of the steroidal oestrogens oestrone and oestradiol: possible mechanism of uterine and mammary cancer development. Hum Reprod Update 7: 273-281, 2001.

9. Ikeda K and Inoue S: Estrogen receptors and their downstream targets in cancer. Arch Histol Cytol 67: 435-442, 2004.

10. Platet N, Cathiard AM, Gleizes M and Garcia M: Estrogens and their receptors in breast cancer progression: a dual role in cancer proliferation and invasion. Crit Rev Oncol Hematol 51: 55-67, 2004.

11. Shellabarger CJ, Stone JP and Holtzman S: Rat differences in mammary tumor induction with estrogen and neutron radiation. J Natl Cancer Inst 61: 1505-1508, 1978.

12. Vassilacopoulou D and Boylan ES: Mammary gland morphology and responsiveness to regulatory molecules following prenatal exposure to diethylstilbestrol. Teratog Carcinog Mutagen 13: 59-74, 1993.

13. Shull JD, Spady TJ, Snyder MC, Johansson SL and Pennington KL: Ovary-intact, but not ovariectomized female ACI rats treated with 17 beta-estradiol rapidly develop mammary carcinoma. Carcinogenesis 18: 1595-1601, 1997.
14. Holtzman S, Stone JP and Shellabarger CJ: Synergism of diethylstilbestrol and radiation in mammary carcinogenesis in female F344 rats. J Natl Cancer Inst 63: 1071-1074, 1979.

15. Shellabarger CJ, McKnight B, Stone JP and Holtzman S: Interaction of dimethylbenzanthracene and diethylstilbestrol on mammary adenocarcinoma formation in female ACI rats. Cancer Res 40: 1808-1811, 1980.

16. Li JJ, Papa D, Davis MF, et al: Ploidy differences between hormone- and chemical carcinogen-induced rat mammary neoplasms: comparison to invasive human ductal breast cancer Mol Carcinog 33: 56-65, 2002.

17. Wiklund J, Wertz $\mathrm{N}$ and Gorski J: A comparison of estrogen effects on uterine and pituitary growth and prolactin synthesis in F344 and Holtzman rats. Endocrinology 109: 1700-1707, 1981.

18. Wiklund J, Rutledge $\mathrm{J}$ and Gorski J: A genetic model for the inheritance of pituitary tumor susceptibility in F344 rats. Endocrinology 109: 1708-1714, 1981.

19. Lloyd RV: Estrogen-induced hyperplasia and neoplasia in the rat anterior pituitary gland. An immunohistochemical study. Am J Pathol 113: 198-206, 1983.

20. Stone JP, Holtzman S and Shellabarger CJ: Neoplastic responses and correlated plasma prolactin levels in diethylstilbestroltreated ACI and Sprague-Dawley rats. Cancer Res 39: 773-778, 1979.

21. Blankenstein MA, Broerse JJ, van Zwieten MJ and van der Molen HJ: Prolactin concentration in plasma and susceptibility to mammary tumors in female rats from different strains treated chronically with estradiol-17 beta. Breast Cancer Res Treat 4: $137-141,1984$ 